\title{
STUDI POPULASI MONYET EKOR PANJANG (Macaca fascicularis) DI PULAU CONDONG DARAT DESA RANGAI KECAMATAN KETIBUNG KABUPATEN LAMPUNG SELATAN
}

\section{(POPULATION STUDY OF THE LONG TAILED MACAQUES (Macaca fascicularis) AT CONDONG TERESTRIAL ISLAND RANGAI VILLAGE SUB DISTRICT OF KETIBUNG SOUTH LAMPUNG REGENCY)}

\author{
Risdiyansyah $^{1)}$, Sugeng P Harianto ${ }^{1)}$, dan Nuning Nurcahyani ${ }^{2)}$ \\ ${ }^{1)}$ Jurusan Kehutanan Fakultas Pertanian Universitas Lampung \\ ${ }^{2)}$ Jurusan Biologi Fakultas Matematika dan Ilmu Pengetahuan Alam Universitas Lampung \\ Jl. Soemantri Brojonegoro no.1 Bandar Lampung, 35145 \\ E-mail : risdiyansyah@rocketmail.com
}

\begin{abstract}
ABSTRAK
Pulau Condong Darat merupakan salah satu pulau yang terletak di kawasan wisata Pasir Putih dan memiliki vegetasi yang alami sehingga dapat dijadikan sebagai kawasan konservasi bagi makhluk hidup. Salah satu makhluk hidup yang ada adalah monyet ekor panjang. Penelitian ini bertujuan untuk mengetahui jumlah individu dan kepadatan populasi monyet ekor panjang (Macacafascicularis) di Pulau Condong Darat. Penelitian ini dilaksanakan tanggal 16 Januari - 5 Februari 2012. Metode pengumpulan data menggunakan metode terkonsentrasi yang dilakukan dengan cara mendatangi titik-titik keberadaan monyet ekor panjang yang telah diketahui. Perhitungan populasi monyet ekor panjang yaitu dengan mencatat waktu dan jumlah individu yang masuk pada setiap titik pengamatan, keluar masuknya monyet ekor panjang pada setiap titik dicatat pada tally sheet agar tidak terjadi pengulangan perhitungan. Pengamatan dilakukan mulai pukul 06.00 WIB sampai18.00 WIB. Dari hasil penelitian dapat diketahui, bahwa jumlah individu monyet ekor panjang (Macaca fascicularis) di Pulau Condong Darat Desa Rangai Kecamatan Ketibung Kabupaten Lampung Selatan adalah140 ekor dengan kepadatan populasi 28 ekor/ha.
\end{abstract}

Kata kunci : kepadatan populasi, Macaca fascicularis, pulau Condong, studi populasi

\section{ABSTRACT}

The Condong Terestrial Island is one of the island belong to tourist area, Pasir Putih, in Rangai village. bThis island has a natural vegetation and become conservation area for all living things. One of them is the long tailed macaques (Macaca fascicularis), or the crabeathing macaques. The objective of this research is to know about the number and the population density of long tailed macaques (Macaca fascicularis) at Condong Terestrial Island. The research has been done from January $16^{\text {th }}$ to February $5^{\text {th }} 2012$. This research was using concentrated method. Data was collected by visiting the existence of long tailed macaques. Population of longtailed macaques was calkulated by noting the time and the number of individuals admitted at any point of observation, the number of crab-eating macaques in and out at any poin wast recorded on tally sheets to avoid repetition of the calculation. The observation was conducted during the daytime started from 6am to 6pm. The result of this research shown that the total number of this long tailed macaques is about 140 individu with population density is about 28 ekor per hectare.

Key words : Condong Island, Macaca fascicularis, population density, population study 


\section{PENDAHULUAN}

Primata adalah salah satu spesies yang terancam punah populasinya dan keberlangsungan hidupnya tergantung upaya konservasi yang akan dilakukan. Monyet ekor panjang (Macaca fascicularis) adalah salah satu satwa liar yang dieksplorasi secara berlebihan. Pengelolaan dan pemanfaatan monyet ekor panjang yang tidak bijaksana dan berlebihan dalam waktu jangka panjang dapat menyebabkan satwa ini terancam punah. Pulau Condong merupakan salah satu tempat tujuan wisata yang memiliki keunikan tersendiri, karena merupakan habitat bagi monyet ekor panjang. Jumlah primata pada habitatnya di alam bebas (hutan) merupakan salah satu bentuk kekayaan dan keanekaragaman (biodiversity) sumber daya alam hayati, karena itu dilindungi, baik perlindungan jumlah individu maupun sebarannya di habitat alaminya (Napitu, Ningtyas, Basari, Basuki, Basori, dan Kurniawan, 2007). Dengan mengetahui jumlah populasi Monyet ekor panjang di tempat ini, maka dapat dilakukan upaya pengelolaan dan pemanfaatannya.

Tujuan dari penelitian ini adalah untuk mengetahui 1) jumlah individu monyet ekor panjang di Pulau Condong Darat, dan 2) kepadatan populasi monyet ekor panjang di Pulau Condong Darat.

\section{METODE PENELITIAN}

Penelitian ini dilaksanakan mulai bulan Januari sampai Februari 2012, di Pulau Condong Darat, Desa Rangai,Kecamatan Ketibung, Kabupaten Lampung Selatan. Alat-alat yang digunakan pada penelitian ini adalah binokuler, kamera, jam tangan, Tally sheet dan alat tulis, sedangkan objek penelitian adalah kelompok monyet ekor panjang. Titik pengamatan pada penelitian ini dibagi menjadi tiga kelompok yaitu titik M1, M2, dan M3.

Data yang dikumpulkan dalam penelitian ini meliputi data primer dan data sekunder. Data primer berupa jumlah individu monyet ekor panjang sedangkan data sekunder berupa karakteristik lokasi penelitian, kondisi vegetasi lokasi penelitian, data umum mengenai monyet ekor panjang dan data tambahan lain mengenai potensi adanya predator monyet ekor panjang. Data primer dikumpulkan menggunakan metode terkonsentrasi (Alikodra, 1980), pengamatan dilakukan dari pukul 06.00 sampai 18.00 WIB. Data sekunder diperoleh melalui studi literatur. Analisis data yang dilakukan meliputi penghitungan kepadatan populasi dengan menggunakan rumus (Alikodra, 1990):

Kepadatan populasi: Jumlah individu(ekor)

Luas areal sensus (ha)

Data yang telah ditabulasikan dianalisis secara deskriptif, didukung dengan data sekunder untuk melengkapi data primer yang diperoleh dari pengamatan di lapangan.

\section{HASIL DAN PEMBAHASAN}

Populasi adalah kelompok kolektif spesies yang sama yang menduduki ruang tertentu dan pada saat tertentu. Berdasarkan hasil pengamatan yang telah dilakukan, jumlah individu monyet ekor panjang yang didapatkan pada titik pengamatan memiliki nilai yang berbeda di tiap titiknya. Data hasil pengamatan populasi monyet ekor panjang tersebut dapat dilihat pada Tabel 1.

Dari Tabel 1 di atas, dapat diketahui bahwa jumlah individu yang ditemukan pada titik (M1) sebanyak 25, pada titik pengamatan (M2) sebanyak 74 ekor, dan titik pengamatan (M3) sebanyak 41 ekor, sehingga jumlah keseluruhan individu dari M1+M2+M3 adalah 140 ekor. Berdasarkan penelitian, monyet ekor panjang lebih banyak ditemukan pada sore hari, hal 
ini dapat dimaklumi karena pada dasarnya satwa diurnal akan aktif pada pagi dan sore hari, karena pada pagi hari monyet ekor panjang beraktivitas untuk mencari makan dan di sore hari monyet ekor panjang pulang ke tempat pohon tidurnya untuk beristirahat. Dari hasil penelitian yang telah dilakukan, populasi monyet ekor panjang yang ada di Pulau Condong Darat menurun dibandingkan jumlah saat didatangkan pada tahun 1997 yaitu sejumlah 400 ekor, pada tahun 2012 jumlah populasi monyet ekor panjang yang ada di Pulau Condong Darat menjadi 140 ekor. Hasil ini menunjukkan bahwa jumlah populasi monyet ekor panjang yang ada di Pulau Condong Darat mengalami penurunan.

Penurunan atau peningkatan populasi dipengaruhi oleh angka kelahiran dan angka kematian, jika angka kelahiran lebih besar daripada angka kematian maka populasi akan meningkat, sebaliknya jika angka kematian lebih besar daripada angka kelahiran maka populasi akan menurun. Menurut hasil wawancara, populasi monyet ekor panjang di Pulau Condong Darat telah mengalami penurunan. Hal ini disebabkan banyak monyet ekor panjang yang mati pada saat kemarau panjang tahun 2011. Musim kemarau tersebut menyebabkan banyak tumbuhan yang menjadi sumber makanan monyet ekor panjang mati akibat kekeringan, sehingga ketersediaan makanan pun berkurang. Penjaga Pulau Condong Darat yang tinggal di sana mengatakan bahwa pada musim kemarau sering ditemukan monyet ekor panjang dalam keadaan mati di pulau tersebut.

Kepadatan populasi ialah besarnya populasi dalam hubungannya dengan suatu unit atau ruang. Nilai kepadatan populasi adalah besaran populasi dalam suatu unit ruang (Alikodra, 1990). Pada umumnya kepadatan populasi dinyatakan dalam bentuk individu per luas areal, sedangkan pada monyet ekor panjang yang memiliki luasan habitat dalam hitungan hektar maka nilai kepadatan populasi monyet ekor panjang dinyatakan dalam bentuk individu per hektar. Nilai kepadatan populasi monyet ekor panjang di Pulau Condong Darat adalah 28 ekor/ha, hasil tersebut lebih kecil dari hasil observasi yang dilakukan oleh Yulianti (2002) dan Irianto (2009) di hutan monyet Tirtosari yaitu 29 ekor/ha dan 82,5 ekor/ha. Hal ini kemungkinan disebabkan karena perbedaan kondisi dari masing-masing habitat monyet ekor panjang. Jumlah individu pada titik M2 lebih besar dibandingkan dengan kepadatan individu yang ada pada titik M1 dan M3. Hal itu diduga terjadi karena adanya perbedaan dari masingmasing kondisi vegetasi dan topografi di M1, M2, dan M3. Kondisi topografi pada titik M1 dan M2 didominasi oleh daerah yang landai, sedangkan pada titik M3 memiliki topografi yang terjal. Topografi di sekitar titik konsentrasi penelitian tempat aktivitas hewan ini relatif landai, hal ini diduga sebagai pertimbangan pemimpin kelompok dalam menjaga keselamatan anggota karena terdapat anakan yang masih memerlukan bimbingan dalam melakukan pergerakan. Relatif kecilnya hutan yang menjadi habitat monyet ekor panjang berpengaruh terhadap kerapatan populasi monyet ekor panjang. Selain itu, Bismark (1984) juga mengatakan bahwa habitat merupakan faktor yang penting untuk kehidupan satwa liar. Berkurangnya jumlah suatu populasi dapat disebabkan juga oleh faktor kematian. Faktor kematian dapat mengurangi kepadatan populasi.

Monyet ekor panjang memiliki tempat-tempat yang dapat digunakan dalam aktivitas sehari-hari untuk mencari makan, minum, bermain, berkembangbiak, dan berlindung/ beristirahat. Tempat-tempat yang fungsinya semacam itu membentuk suatu kesatuan yang disebut habitat. Dalam pemilihan habitatnya, monyet ekor panjang melakukan seleksi terhadap daya dukung yang terdapat di lokasi tersebut. Faktor-faktor yang mempengaruhi primata dalam memilih habitat antara lain adalah:

1. Ketersediaan pakan

Monyet ekor panjang merupakan salah satu jenis satwa pemakan buah (frugivorous), dan mempunyai kebiasaan makan yang sangat selektif. Mereka memakan bunga, buah, dan daun-daun muda yang terdapat pada tumbuhan tertentu. Makanan merupakan salah satu faktor yang sangat penting dalam penunjang keberlangsungan hidup dan perkembangan 
makhluk hidup. Potensi pakan satwa tergantung pada kondisi fisik maupun biotik dari suatu habitat, apabila suatu habitat banyak mengalami gangguan akan berpengaruh besar terhadap sumber pakan dan keadaan populasi satwa. Kondisi habitat dikatakan baik apabila habitat tersebut memiliki ketersediaan pakan yang cukup serta faktor-faktor yang lainnya, baik fisik maupun biotik yang dapat mendukung keberlangsungan hidupnya. Di Pulau Condong Darat terdapat sebelas jenis tumbuhan yang menjadi makanan monyet ekor panjang. Bagian tumbuhan yang dimakan meliputi daun, bunga, dan buah. Jenis tumbuhan tersebut dapat dilihat pada Tabel 2.

Tabel 1. Rekapitulasi jumlah individu monyet ekor panjang (Macaca fascicularisi) di Pulau Condong Darat.

\begin{tabular}{|c|c|c|c|c|}
\hline No & Lokasi/Koordinat & $\begin{array}{c}\text { Jumlah individu } \\
\text { (ekor) }\end{array}$ & Jumlah kelompok & Keterangan \\
\hline 1. & $\begin{array}{c}\mathrm{M} 1 \\
0538174 \mathrm{mT} \\
9386759 \mathrm{mU}\end{array}$ & 25 & 3 & Cerah \\
\hline 2. & $\begin{array}{c}\text { M 2 } \\
0538174 \mathrm{mT} \\
9386933 \mathrm{mU}\end{array}$ & 74 & 9 & Cerah \\
\hline 3. & $\begin{array}{c}\text { M 3 } \\
0538130 \mathrm{mT} \\
9387004 \mathrm{mU}\end{array}$ & 41 & 5 & Cerah \\
\hline & Jumlah Total & 140 & 17 & \\
\hline
\end{tabular}

Keterangan :

M 1 = Lokasi Pengamatan ke-1

M 2 = Lokasi Pengamatan ke-2

M 3 = Lokasi Pengamatan ke-3

Tabel 2. Nama tumbuhan dan bagian tumbuhan yang dimakan monyet ekor panjang.

\begin{tabular}{lllccc}
\hline \multirow{2}{*}{ No } & \multicolumn{2}{c}{ Nama lokal } & \multicolumn{2}{c}{ Nama ilmiah } & \multicolumn{3}{c}{ Bagian yang dimakan } \\
\cline { 3 - 5 } 1. & Aren & Arenga pinnata & $*$ & Bunga & Buah \\
2. & Beringin & Ficus benjamina & $*$ & $*$ & $*$ \\
3. & Kelapa & Cocos nucifera & & $*$ & $*$ \\
4. & Ketapang & Terminalia cattapa & & $*$ & \\
5. & Kopi & Coffea sp & $*$ & & $*$ \\
6. & Mangga & Mangifera indica & & $*$ & $*$ \\
7. & Nangka & Artocarpus integra & & $*$ & $*$ \\
8. & Rambutan & Nephelium lappaceum & & $*$ & $*$ \\
9. & Randu & Ceiba petandra & & $*$ & $*$ \\
10. & Tangkil & Gnetum gnemon & $*$ & $*$ & $*$ \\
11. & Waru & Hibiscus tiliaceus & $*$ & $*$ & $*$ \\
\hline
\end{tabular}

Keterangan : (*) Bagian tumbuhan yang dimakan.

Jenis tumbuhan yang dimakan monyet ekor panjang yaitu : aren (Arenga pinnata) bagian yang dimakan adalah daun dan buah; beringin (Ficus benjamina) bagian yang dimakan adalah daun, bunga, dan buah; kelapa (Cocos nucifera) bagian yang dimakan adalah bunga dan buah; ketapang (Terminalia cattapa) bagian yang dimakan adalah bunga; kopi (Coffea 
sp) bagian yang dimakan adalah daun dan buah; mangga (Mangifera indica) bagian yang dimakan adalah buah; nangka (Artocarpus integra) bagian yang dimakan adalah buah; rambutan (Nephelium lappaceum) bagian yang dimakan adalah buah; randu (Ceiba petandra) bagian yang dimakan adalah bunga dan buah; tangkil (Gnetum gnemon) bagian yang dimakan adalah daun, bunga, dan buah; waru (Hibiscus tiliaceus) bagian yang dimakan adalah daun, bunga, dan buah. Menurut Anon (2001) dikutip Chandra (2006), selain jenis tumbuhan yang menjadi makanan monyet ekor panjang berupa daun, bunga, dan buah-buahan, juga memakan bermacam-macam makanan termasuk kulit pohon, tunas, biji, serangga, telur burung, bahkan lempung (tanah liat). Monyet ekor panjangyang memakan tanah liat kemungkinan untuk mendapatkan mineral-mineral yang terkandung di dalam tanah liat tersebut. Kebiasaan monyet ekor panjang memakan telur burung kadangkadang juga anak burung menjadikannya sebagai pemangsa sarang (nest predators).

2. Satwa lain (predator)

Menurut Bismark (1984) struktur hutan berpengaruh nyata terhadap satwa liar yang tinggal di dalamnya. Di dalam hutan banyak dijumpai berbagai jenis satwa yang hidup berdampingan, saling berinteraksi antar satu samalain membentuk suatu rantai makanan yang tak terpisahkan. Suatu hutan tidak hanya dihuni oleh satu jenis satwa liar, tetapi juga memungkinkan terdiri dari beberapa jenis satwa yang hidup di dalamnya baik sebagai tempat tinggal sementara, sebagai tempat bermigrasi, maupun sebagai tempat tinggal hidup dan berkembang biak. Manusia dan hewan peliharaan (ternak) juga termasuk anggota masyarakat, biotik yang mempunyai peranan penting terhadap kelestarian habitat beserta lingkungannya (Alikodra, 1990).

Berbagai jenis satwa yang terdapat di habitat monyet ekor panjang Pulau Condong Darat yaitu, biawak (Varanus salvator), burung kutilang (Pycnonotus bimaculatus), burung gagak (Corvus corax), burung walet (Collacalia fuchiphagus), bajing (Callosciurus notatus). Satwa-satwa yang dijumpai di Pulau Condong Darat merupakan jenis satwa bukan predator (pemangsa) sehingga tidak mengancam dan mengganggu kehidupan monyet ekor panjang. Pulau Condong Darat dijadikan sebagai tempat rekreasi yang dikelola oleh manusia, keadaan ini menjadi salah satu faktor bagi kelestarian monyet ekor panjangyang ada di dalamnya. Frekuensi dan intensitas keluar masuknya pengunjung di Pulau Condong Darat mengakibatkan perubahan perilaku monyet ekor panjang tersebut. Monyet ekor panjang menjadi takut bila banyak pengunjung yang datang ke Pulau Condong Darat tersebut.

3. Kondisi Vegetasi

Vegetasi yang ada pada satu tempat merupakan salah satu faktor yang penting karena merupakan komponen dari habitat primata. Kondisi vegetasi yang ada di Pulau Condong Darat masih berupa hutan alami, karena tumbuhan yng tumbuh di Pulau Condong Darat tumbuh secara alami tumbuhan penyusun vegetasi yang menjadi tempat hidup monyet ekor panjang tumbuh secara alami. Menurut Nainggolan (2011) monyet ekor panjang merupakan jenis satwa liar yang hidupnya di atas pepohonan (arboreal), karena hidupnya di atas pepohonan maka keberadaan pohon tidak bisa dipisahkan dari kehidupan monyet ekor panjang. Pohon penyusun vegetasi bagi primata berguna untuk tempat beristirahat, bersarang, bermain, sumber pakan dan membesarkan serta memperbanyak keturunannya. Hampir semua jenis primata memilih jenis pohon-pohon yang tinggi dan tajuknya lebat seperti yang dijelaskan Whitten (1980) dikutip Nainggolan (2011) bahwa pemilihan pohon tinggi sebagai pohon tempat tidur bertujuan untuk mengurangi resiko primata dari predator termasuk ular dan burung pemangsa. Kerapatan vegetasi di Pulau Condong Darat yang ada di dalam areal pergerakan monyet ekor panjang cukup rapat dan terdiri dari berbagai macam jenis pohon yang bisa dijadikan sumber pakan bagi monyet ekor panjang. Pergerakan harian (home range) monyet ekor panjang berbentuk elips dengan jarak jelajah 
$\pm 300 \mathrm{~m}$ (untuk bagian hutan alam yang terdeteksi, sedangkan sebagian lagi terdiri dari semak dengan kemiringan lereng $\pm 45^{\circ}$ ), hal ini karena luas Pulau Condong Darat yang tidak terlalu luas serta perilaku manusia yang walaupun tidak secara langsung mengganggu perilaku monyet ekor panjang, akan tetapi mengurangi keleluasaan satwa liar untuk beraktifitas (Febriyanti, 2010).

Populasi monyet ekor panjang secara umum masih dianggap aman sehingga CITES dan IUCN Redlist mengkategorikannya dalam status Least Concern. Least Concern adalah istilah yang digunakan oleh Persatuan Internasional untuk konservasi alam (IUCN) untuk berbicara tentang hewan yang tidak terancam punah. Least Concern (LC) adalah kategori dari IUCN yang ditugaskan untuk mengetahui speies yang masih ada atau taksa (peringkat kelompok organisme) lebih rendah yang telah dievaluasi, tetapi tidak memenuhi syarat untuk setiap kategori lainnya. Dengan demikian spesies tersebut tidak memenuhi syarat sebagai satwa yang terancam punah. Bahkan di Indonesia, primata ini juga bukan termasuk salah satu binatang yang dilindungi. Hewan ini merupakan jenis kera yang paling umum dikenal karena penyebarannya yang luas dan sifatnya sangat mudah beradatapsi dengan lingkungan yang baru/lingkungan manusia. Pada habitat alamnya, populasi jenis ini masih melimpah dan di beberapa tempat menjadi hama tanaman pangan yang ditanam di tepi hutan. Akibat perburuan besar-besaran yang terus terjadi, pemanfaatan monyet ekor panjang khususnya untuk pasar ekspor telah diatur dalam Keputusan Menteri Kehutanan Nomor: 26/Kpts-II/94 tanggal 20 Januari 1994 tentang Pemanfaatan jenis Monyet Ekor Panjang (M. fascicularis), Beruk (M. nemestrina), dan Ikan Arwana (Scleropagus formosus) untuk keperluan ekspor. Dalam peraturan tersebut pemanfaatan monyet ekor panjang untuk keperluan ekspor harus berasal dari hasil penangkaran. Meskipun monyet ekor panjang bukan satwa yang dilindungi dan populasinya masih banyak bahkan di beberapa kawasan lindung pernah diberitakan kelebihan populasi monyet jenis ini dan di beberapa daerah sering menjadi hama para petani, bukan berarti keberadaan satwa ini aman. Karena monyet ekor panjang tidak termasuk satwa yang dilindungi, satwa jenis ini paling rentan terhadap eksploitasi, baik diburu, diperdagangkan, dan dijadikan objek tontonan. Ditambah dengan tingkat deforestasi yang terjadi dan penyempitan luas hutan di Indonesia, bukan tidak mungkin monyet ekor panjang akan ikut terancam. Namun demikian usaha-usaha untuk menjaga populasinya di alam harus tetap dilakukan. Karena tekanan terhadap populasi kera ini kian hari kian menunjukkan gejala yang mengkhawatirkan dan terus mengalami penurunan.

\section{SIMPULAN}

Berdasarkan hasil penelitian dapat disimpulkan bahwa di Pulau Condong Darat desa Rangai Kecamatan Ketibung Kabupaten lampung Selatan adalah sebagai berikut:

1. Jumlah individu monyet ekor panjang adalah 140 ekor.

2. Kepadatan populasi monyet ekor pan-jang adalah 28 ekor/ha.

\section{DAFTAR PUSTAKA}

Alikodra, H. S. 1980. Dasar-Dasar Pembinaan Margasatwa. Fakultas Kehutanan Institut Pertanian Bogor. Bogor.

. 1990. Pengelolaan Satwa Liar. Fakultas Kehutanan Institut Pertanian Bogor. Bogor.

Bismark, M. 1984. Biologi dan Konservasi Primata di Indonesia. Buku. Penerbit Fakultas Pascasarjana IPB. Bogor.

Chandra, D. 2006. Analisis habitat monyet ekor panjang (Macaca fascicularis Raffles) di Bukit Banten Kelurahan Sidodai Kecamatan Kedaton Bandar Lampung. (Skripsi). 
Jurusan Manajemen Hutan Fakultas Pertanian Universitas Lampung. Bandar Lampung. Tidak Dipublikasikan.

Febriyanti, D. 2010. Studi perilaku harian kelompok monyet ekor panjang (Macaca fascicularis) di Pulau Condong Darat Desa Rangai Kecamatan Ketibung Kabupaten Lampung Selatan. (Skripsi). Jurusan Manajemen Hutan Fakultas Pertanian Universitas Lampung. Bandar Lampung. Tidak Dipublikasikan.

Nainggolan, V. 2011. Identifikasi satwa liar jenis primata di repong damar Pekon Pahmungan Kecamatan Pesisir Tengah Krui Lampung Barat. (Skripsi). Universitas Lampung. Lampung. Tidak Dipublikasikan.

Napitu, P. J., R. Ningtyas, I. Basari, T. Basuki, A.F. Basori, Uiam, D. Kurniawan. 2007. Laporan lapangan konservasi satwa liar. Diakses 11 Februari 2011. http://C:/Documents and Settings/ owner/My Documents/.html. 
Vol. 2 No. I. Januari 2014 (41-48)

Halaman ini sengaja dikosongkan 